\title{
Preclinical Immunological Evaluation of an Intradermally Administered Heterologous Vaccine Against SARS-CoV-2 Variants
}

Qihan Li ( $\square$ imbcams_QHLi@163.com )

Institute of Medical Biology, Chinese Academy of Medical Sciences

Shengtao Fan

Institute of Medical Biology, Chinese Academy of Medicine Science \& Peking Union Medical College

Kang Xiao

National Institute for Viral Disease Control and Prevention, Chinese Center for Disease Control and

Prevention

\section{Dandan Li}

Institute of Medical Biology, Chinese Academy of Medical Sciences https://orcid.org/0000-0002-3527-

3522

\section{Heng Zhao}

Institute of Medical Biology, Chinese Academy of Medical Sciences and Peking Union Medical College

Jingjing Zhang

Institute of Medical Biology, Chinese Academy of Medical Sciences

Li Yu

Institute of Medical Biology, Chinese Academy of Medical Sciences

Penglan Chang

Institute of Medical Biology, Chinese Academy of Medical Sciences

Shuangli Zhu

National Institute for Viral Disease Control and Prevention, Chinese Center for Disease Control and

Prevention, Beijing, People's Republic of China

\section{Xingli Xu}

Institute of Medical Biology, Chinese Academy of Medical Sciences and Peking Union Medical College

\section{Yun Liao}

Institute of Medical Biology, Chinese Academy of Medicine Science \& Peking Union Medical College

\section{Tianjiao Ji}

National Institute for Viral Disease Control and Prevention, Chinese Center for Disease Control and

Prevention, Beijing, People's Republic of China

\section{Guorun Jiang}

Institute of Medical Biology, Chinese Academy of Medical Sciences and Peking Union Medical College 
National Institute for Viral Disease Control and Prevention, China CDC

\section{Fengyuan Zeng}

Institute of Medical Biology, Chinese Academy of Medical Sciences

\section{Suqin Duan}

Institute of Medical Biology, Chinese Academy of Medical Sciences

\section{Baicheng Xia}

National Institute for Viral Disease Control and Prevention, China CDC

\section{Lichun Wang}

Institute of Medical Biology, Chinese Academy of Medical Sciences

\section{Fengmei Yang}

Institute of Medical Biology, Chinese Academy of Medical Sciences \& Peking Union Medical College

\section{Zhanlong He}

Institute of Medical Biology, Chinese Academy of Medical Sciences \& Peking Union Medical College

\section{Yang Song}

National Institute for Viral Disease Control and Prevention, China CDC

\section{Pingfang Cui}

Institute of Medical Biology, Chinese Academy of Medicine Science \& Peking Union Medical College

\section{Xiaolei Li}

National Institute for Viral Disease Control and Prevention, China CDC

\section{Yaxing Zhang}

Institute of Medical Biology, Chinese Academy of Medical Sciences

\section{Bangyi Zheng}

Institute of Medical Biology, Chinese Academy of Medical Sciences

\section{Ying Zhang}

Institute of Medical Biology, Chinese Academy of Medical Sciences

\section{Wen-Bo Xu}

National Institute for Viral Disease Control and Prevention, Chinese Center for Disease Control and Prevention

\section{Article}

Keywords: SARS-CoV-2, variants, intradermal administration, vaccine

Posted Date: October 12th, 2021

DOl: https://doi.org/10.21203/rs.3.rs-745722/v1

License: (c) (i) This work is licensed under a Creative Commons Attribution 4.0 International License. Read Full License 


\section{Abstract}

The recent emergence of new variants in the COVID-19 pandemic has led to new requirements for vaccines, with a focus on the capacity of vaccines to elicit high levels of neutralizing antibodies with specific recognition of $S$ antigen variants based on the characterized vaccines licensed for use. A new strategy involving a heterologous vaccine composed of one or two doses of inactivated vaccine and a boost with the S1 protein with mutations (K-S) administered via the intradermal route was designed in this work and was found to improve immune efficacy by increasing neutralizing antibody titers and promoting specific $T$ cell responses against 5 variants of the RBD peptide. A viral challenge test with the B.1.617.2 (Delta) variant confirmed that the both schedules of " $1+1$ " and " $2+1$ " administration ensured a clinical protective effect against this strain. All of these results not only suggested the feasibility of our strategy for protecting against new variants but also provided a technical pathway to enhance the anamnestic immune response in the immunized population.

\section{Introduction}

The massive pandemic of COVID-19 caused by SARS-CoV-2, which was identified as a member of the $\beta$ group of the coronavirus family, has led to approximately 180 million infected patients and 3.8 million deaths since the end of $2019^{1}$, and it has again aroused public concern with the appearance of various variant strains worldwide $2,3,4,5$. Currently, there is an urgent need to develop a new generation of vaccines with known immunization modes to enable defense against variants; these vaccines should not only elicit high-level neutralizing antibodies in vaccinated individuals but also possess the technical capacity for prompt industrialization of responses to the appearance of new variants based on the realworld situation that more than one billion people have been immunized by approximately 10 different licensed vaccines in different areas of the world ${ }^{6}$. For this purpose, several uncertainties based upon published data were considered. First, how to induce a high level of neutralizing antibodies and how to maintain this neutralizing antibody level in immunized individuals have not been clarified in the presented data. However, there have been many reports showing a wide range of neutralizing antibody titers to be effective for viral challenge tests in animal studies ${ }^{7,8}$. Various surveys of convalescent serum from infected patients also indicated a downward trend of neutralizing antibodies over half a year 9,10 . Similarly, our previous observation in a clinical trial of an inactivated vaccine suggested that neutralizing antibodies diminished to very low levels 6 months after immunization with two doses at intervals of 14 or 28 days ${ }^{11}$. Second, recent studies on isolated variants suggested that immune sera enable neutralization of variant strains with higher titers than prototype strains ${ }^{12,13,14,15}$. Based on these data, it could be inferred that a vaccine with the capacity to maintain neutralizing antibody levels for a longer time and enhance specific immune recognition of variants should be a better candidate for further application. This is because we face the challenge of responding to the rapid appearance of variants during the global pandemic and substantial time is required to develop any new vaccine and to apply for authorization to conduct clinical trials and perform them in three phases. In this study, a new heterologous vaccine strategy was designed, in which one immunization with $1 / 5$ to $1 / 3$ of the amount 
of antigen used in an inactivated vaccine that was authorized for clinical trials was administered via the intradermal route, followed by one boost of eukaryotically expressed S1 protein (K-S) with 6 mutated amino acids, similar to the sequences in the B.1.351, B.1.617 and B.1.1.7 strains ${ }^{16,17}$. The inactivated vaccine was in a phase III trial and approved for emergency use in China with a formulation including a $150 \mathrm{U} /$ dose associated with Al adjuvant administered in two injections at an interval of 14 or 28 days ${ }^{18}$. The results suggested that boosting this optimized S1 protein, based upon basic immunization with an inactivated vaccine, can elicit a high level of neutralizing antibody with the capacity to cross-neutralize three variants associated with a specific $T$ cell response against these variant antigens. Importantly, a viral challenge test with the B.1.617.2 strain showed that $\mathrm{ACE}^{+/+}$mice immunized with this heterologous vaccine were capable of preventing and restraining viral infection and proliferation in tissues, and no pathological lesions were found in the mice. All observations suggested that this heterologous vaccine administered via the intradermal route can not only ameliorate the immune effect, probably by improving the innate immune response with subsequent activation of adaptive immunity, but also make it technically feasible for a cell seed library containing strains transfected with eukaryotic vectors expressing S1 protein, including various variants preconstructed based upon genetic prediction of sequences with a high frequency of mutation, to be realized for emergency development of vaccines as new variant strains are found.

\section{Material And Methods}

\section{Cells and virus}

The Vero cell strain WHO Vero 10-87 used to produce the SARS-CoV-2 inactivated vaccine, and to detect neutralizing antibody in this study was provided by the WHO ${ }^{18,19}$. The cells were grown in MEM-5\% FCS medium in culture plates to form monolayers for various assays or were grown in microcarriers in bioreactors with an MEMbased protocol for the production of inactivated vaccines. $\mathrm{CHO}$ cells expressing the S1 protein with mutated sites were purchased from SUQIAO. Co. and were grown in RPMI 1640-8\% FCS medium with a bioreactor-based standard protocol ${ }^{20}$. Two strains of SARS-CoV-2 with sequences of the S protein from the prototype strain (Wuhan strain) KMS-1 (MT226610.1) and KMS-2 were isolated from Yunnan Infectious Hospital in January 2020. The variant strains B.1.351, B.1.617.2 (Delta) and Wuhan used for cross-neutralization assays and challenge tests were provided by the National Institute for Viral Disease Control and Prevention, China CDC.

\section{SARS-CoV-2 inactivated vaccine}

The SARS-CoV-2 inactivated vaccine was developed by the Institute of Medical Biology (IMB), Chinese Academy of Medical Sciences (CAMS). In brief, the virus strain (KMS-1) for the vaccine was inoculated into medium containing Vero cells. Dual inactivation of virus harvested from Vero cells was performed with formaldehyde ( $\mathrm{HCHO}, 1: 4000 ; 48 \mathrm{~h}$ ) to partially disrupt the viral membrane, followed by betapropiolactone (BPL, 1:2000; $48 \mathrm{~h}$ ) to disrupt the structure of the viral genome. The viral antigen content was measured via enzyme-linked immunosorbent assay (ELISA). The vaccine contained $150 \mathrm{U}$ of 
inactivated SARS-CoV-2 viral antigen adsorbed to the adjuvant $\mathrm{Al}(\mathrm{OH})_{3}$ (Al amount, $0.0875 \mathrm{mg}$ ), suspended in $0.5 \mathrm{ml}$ of buffered saline and administered to the population aged 18-80 years via the intramuscular route.

\section{Recombinant antigen (K-S) from the S1 protein with 6 mutated sites}

The optimized S1 (K-S) sequence with 6 mutated sites (G1251T (K417N), T1355G (L452R), G1450C (E484Q), A1501T (N501Y), A1841G (D614G) and C2042G (P681R)) was designed for construction of a eukaryotic expression vector (patent application submitted). The plasmid was transfected into $\mathrm{CHO}$ cells according to a standard protocol. The identified and screened clone was grown in RPMI 1640 medium for the construction of libraries of primary seeds, main seeds and working seeds followed by qualification assays based on requirements from the Chinese FDA. The K-S protein was expressed under optimized conditions in middle-scale production. After purification by chromatography, the purified antigen (10 $\mu \mathrm{g} /$ dose) was formulated with $\mathrm{Al}(\mathrm{OH})_{3}$ adjuvant (Al amount, $0.0175 \mathrm{mg} /$ dose) for further administration in an immunological study.

\section{Animal experiment and ethics approval}

The animal experiment was designed and performed according to the principles in the "Guide for the Care and Use of Laboratory Animals" and the "Guidance for Experimental Animal Welfare and Ethical Treatment". The protocols were reviewed and approved by the Experimental Animal Management Association of the IMB, CAMS (approval number: DWSP 202003 005). All animals were fully under the care of veterinarians at the IMB, CAMS.

\section{Prepare immune serum against K-S protein}

The rabbits were immunized intramuscularly three times with the K-S antigen attaching to $\mathrm{Al}(\mathrm{OH})_{3}$ adjuvant) at intervals of 14 days. The immune serum were obtained on day 14 after the last injection.

\section{Western blots}

Proteins were separated by $12 \%$ SDS-PAGE and transferred to polyvinylidene difluoride (PVDF) membranes. The membranes were blocked with 5\% BSA-TBST (Sigma-Aldrich, St. Louis, MO, USA), treated with convalescent or immunized serum, and then treated with HRP-conjugated goat anti-human IgG $(\mathrm{H}+\mathrm{L})$ (4A Biotech, Beijing, China) or HRP-conjugated goat anti-rabbit IgG (Sigma, Shanghai, China). Finally, the PVDF membrane was covered with ECL ultrasensitive chemiluminescence reagent (Beyotime, Jiangsu, China) and placed in a Bio-Rad gel imager for exposure and color development. The recombinant S1 protein (Sanyou Biopharmaceuticals Co., Ltd.), the unmutation spike RBD protein (SinoBiological Co., Ltd, China), single-point mutation RBD protein (K417N, L452R, E484Q, N501Y, N439K, A520V; SinoBiological Co., Ltd) were used in this study.

\section{Design of the study to monitor the local innate immune response in injected tissues}


In total, 48 C57 mice (purchased from Shanghai Model Organisms Center, Inc., China) were divided into 4 subgroups with 12 mice each. Mice in the ID-V group were immunized intradermally once with $30 \mathrm{U}$ of inactivated vaccine. Mice in the ID-K group were immunized once intradermally with $10 \mu \mathrm{g}$ of K-S protein. Mice in the IM-V group were immunized once intramuscularly with $30 \mathrm{U}$ of inactivated vaccine. Mice in the IM-K group were immunized once with $10 \mu \mathrm{g}$ of K-S protein. At 12, 24, and 48 hours post immunization, the local skin or muscle tissues of immunized mice in the ID-V and IM-V groups were obtained after euthanization (Fig. S1a). Blood samples from the remaining mice were obtained on day 14 after boost immunization.

\section{Design of the study to comparing intradermal and intramuscularly injection}

8 macaques aged 2-3 years, was divided into two subgroups with 4 macaques in each subgroup. ID: Macaques were immunized intradermally once with $30 \mathrm{U}$ of inactivated vaccine and bled for antibody assays on day 14 post immunization for antibody assays. IM: Macaques were immunized intramuscularly twice with $150 \mathrm{U}$ of inactivated vaccine at an interval of 14 days, and bled for antibody assays on day 14 after boost immunization for antibody assays. (Fig. S1b).

\section{Design of the animal immunological and viral challenge study}

Mouse study: Group A (MA), which included $48 \mathrm{ACE}^{+/+}$transgenic mice (purchased from Shanghai Model Organisms Center, Inc., China), was divided into 4 subgroups with 12 mice in each subgroup. MA-1: The mice were immunized intradermally with $30 \mathrm{U}$ of inactivated vaccine per mouse (this antigen amount is equal to $1 / 5$ of that used intramuscularly). At 28 days post immunization, the mice were bled for antibody assays and boosted with the expressed K-S antigen (10 $\mu \mathrm{g} / \mathrm{dose})$, followed by collection of blood samples at days 14 post boost for antibody assays. On day 28 post boost with the K-S antigen, all mice were challenged with the B.1.617.2 strain for observation of protective efficacy. MA-2: The mice were immunized intradermally with $50 \mathrm{U}$ of inactivated vaccine per mouse (this antigen amount is equal to $1 / 3$ of that used intramuscularly) followed by the same operation described for MA-1. MA-3: The mice were immunized twice with $30 \mathrm{U} /$ dose at an interval of 14 days, and the boost with K-S antigen (10 $\mu \mathrm{g} /$ dose) was administered on day 14 after the 2 nd dose of inactivated vaccine; this was followed by the same procedure described for MA-1, including bleeding and the challenge test. MA-4: The mice were immunized twice with $50 \mathrm{U} /$ dose at an interval of 14 days, and the K-S antigen was used for boosting on day 14 after the 2 nd inactivated vaccine; this was followed by the same procedure described for MA-3. In the control observation, the same groups immunized and challenged were set up for recording of mice survival rate.

Group B (MB), which included $24 \mathrm{ACE}^{+/+}$transgenic mice, was divided into 2subgroups with 12 mice in each subgroup. MB-1: The mice were inoculated with PBS (10 mmol) firstly and then immunized with K-S antigen ( $10 \mu \mathrm{g} /$ dose) on day 28 , followed by viral challenge on day 56 . MB-2: The mice were injected two 
times intradermally with the $\mathrm{Al}(\mathrm{OH})_{3}$ adjuvant (Al amount, $0.014-0.021 \mathrm{mg} /$ dose) at an interval of 14 days, followed by viral challenge on day 56. Blood samples were obtained on days 28 and 42 for antibody assays, as well as MA group. In the control observation, the same groups immunized and challenged were set up for recording of mice survival rate.

Group C (MC), which included 48 C57 mice, was divided into 4 subgroups with 12 mice in each subgroup. MC-1: The mice were immunized intradermally with $30 \mathrm{U}$ of inactivated vaccine per mouse and bled for antibody assays on day 28 , and they were boosted with the expressed K-S antigen ( $10 \mu \mathrm{g} / \mathrm{dose})$ followed by bleeding on days 14, 28 and 56 after boost immunization for antibody assays. MC-2: The mice were immunized intradermally with $50 \mathrm{U}$ of inactivated vaccine per mouse, followed by the same procedure described for MC-1. MC-3: The mice were immunized twice with $30 \mathrm{U}$ of inactivated vaccine per mouse at an interval of 14 days, and the K-S antigen ( $10 \mu \mathrm{g} /$ dose) was used for boost immunization on day 14 after the 2 nd dose of inactivated vaccine, followed by the same procedure described for MC-1. MC-4: The mice were immunized twice with $50 \mathrm{U}$ of inactivated vaccine per mouse at an interval of 14 days, and the $\mathrm{K}$-S antigen was used for boost immunization on day 14 after the 2 nd dose of inactivated vaccine, followed by the same procedure described for MC-1.

Group D (MD), which included 36 C57 mice, was divided into 3 subgroups with 12 mice in each subgroup. MD-1: The mice were inoculated with PBS firstly and then immunized with K-S antigen on day 28 , followed by bleeding on days $28,42,56$ and 84 post the first immunization for antibody assays. MD-2: The mice were injected twice intradermally with the $\mathrm{Al}(\mathrm{OH})_{3}$ adjuvant at an interval of 14 days, followed by bleeding on days $28,42,56$ and 84 post the first immunization for antibody assays. MD-3: The mice were immunized twice intradermally with the inactivated influenza vaccine at an interval of 14 days, followed by bleeding at days $28,42,56$ and 84 post the first immunization for antibody assays (Fig. 1a).

Rhesus macaque study: Group E (RE), which included 8 macaques aged 2-3 years, was divided into two subgroups with 4 macaques in each subgroup. RE-1: Macaques were immunized intradermally with $30 \mathrm{U}$ of inactivated vaccine and bled for antibody assays on day 28 post immunization, and they were boosted with the K-S antigen ( $10 \mu \mathrm{g} /$ macaque) followed by bleeding on days 14 and 28 post boost immunization for antibody assays. RE-2: Macaques were immunized intradermally with $50 \mathrm{U}$ of inactivated vaccine each, followed by the same procedure described for RE-1. Group F (RF), which included 8 macaques, was divided into two subgroups, with 4 macaques in each subgroup. RF-1: Macaques were immunized twice with $30 \mathrm{U}$ of inactivated vaccine at an interval of 14 days, and the K-S antigen was used for boost immunization on day 14 after the 2 nd dose of inactivated vaccine, followed by the same procedure described for RE-1. RF-2: The macaques were immunized twice with $50 \mathrm{U}$ of inactivated vaccine per macaque at an interval of 14 days, and the K-S antigen was used for boost immunization on day 14 after the 2nd dose of inactivated vaccine, followed by the same procedure described for RE-1 (Fig. 1b).

\section{Viral challenge test with the B.1.617.2 strain in immunized $\mathrm{ACE}^{+/+}$transgenic mice}


Immunized $\mathrm{ACE}^{+/+}$transgenic mice were infected with the B.1.617.2 strain $\left(1 \times 10^{3} \mathrm{CCID}_{50} /\right.$ dose $)$ via nasal spray under ABSL-3 laboratory conditions on day 56 after the first immunization. All animals were monitored daily for clinical signs. Pharyngeal secretion and nasal secretion samples were obtained daily after infection. On days 3, 7 and 11, three mice in each group were euthanized for viral load measurement and pathological observation. The remaining mice were euthanized after completing the viral challenge.

\section{Neutralization assay for different viral strains}

Heat-inactivated serum was serially diluted and coincubated with live virus ( $100 \operatorname{lgCCID}_{50} /$ well) for $2 \mathrm{~h}$ at $37^{\circ} \mathrm{C}$. Then, $100 \mu \mathrm{l}$ of the Vero cell suspension $\left(10^{5} \mathrm{cell} / \mathrm{s} / \mathrm{ml}\right)$ was added to the mixture, followed by incubation at $37^{\circ} \mathrm{C}$ in a $5 \% \mathrm{CO}_{2}$ atmosphere for 7 days. Cytopathic effects (CPEs) were observed and assessed with an inverted microscope (Nikon) to determine the neutralizing antibody titer of the serum. The geometric mean titers (GMTs) of neutralizing antibodies were measured.

\section{ELISA}

ELISAs were conducted with antibodies against the $S$ protein and the $N$ protein. $S$ and $N$ proteins (Sanyou Biopharmaceuticals Co., Ltd., Shanghai, China) were used to coat ELISA plates (Corning, NY, USA) at a concentration of $5 \mu \mathrm{g} /$ well, and the plates were incubated at $4^{\circ} \mathrm{C}$ overnight. The plates were blocked with $5 \%$ BSA, incubated with serum samples and followed by adding an HRP-conjugated antibody (Abcam, MA, USA), and immune complexes were visualized using TMB substrate (Solarbio, Beijing, China) as described in a previous report ${ }^{21}$. The absorbance of each well at $450 \mathrm{~nm}$ was measured using an ELISA plate reader (Gene Company, Beijing, China). The antibody serum samples that yielded OD values at least 2.1-fold higher than that of the negative control at a test sample dilution of 1:400 were defined as positive. The endpoint titer (ET) was defined as the highest serum dilution that yielded a positive OD value. The GMT was calculated as the geometric mean of the ETs of the positive serum samples in each group.

\section{Elispot assay}

Peripheral blood mononuclear cells (PBMCs) were isolated from blood by a lymphocyte isolation technique (Ficoll-Paque PREMIUM; GE Healthcare, Piscataway, NJ, USA). An ELISPOT assay was performed with a Mouse or Monkey IFN-y ELISPOT Kit (Mabtech, Cincinnati, OH, USA) according to the manufacturer's protocol. All samples were plated in duplicate wells. The different stimulus, namely, single-point mutation RBD peptide (K417N, L452R, E484Q, and N501Y; SinoBiological Co., Ltd), two-point mutation RBD protein (L452R + E484Q; SinoBiological Co., Ltd) and recombinant N protein (Sanyou Biopharmaceuticals Co., Ltd.), were added to separate wells, respectively. The positive control was phytohemagglutinin (PHA). The plate was incubated at $37^{\circ} \mathrm{C}$ for $24 \mathrm{~h}$, after which the cells were removed and the spots developed. The colored spots were counted with an ELISPOT reader (CTL, Shaker Heights, $\mathrm{OH}, \mathrm{USA})$.

\section{Electron microscopy}


Purified inactivated SARS-CoV-2 preparations were coincubated with convalescent serum or with a monoclonal antibody (mAb) against the S protein (mAb-S) or the $\mathrm{N}$ protein ( $\mathrm{mAb}-\mathrm{N})$ (Solarbio, Beijing, China) at $37^{\circ} \mathrm{C}$ for $24 \mathrm{~h}$, stained with $1 \%$ phosphotungstic acid and observed using a transmission electron microscope (Hitachi, Kyoto, Japan).

\section{Transcriptional profile of innate immune signaling molecules in local tissues inoculated with the vaccine}

Skin tissue samples were homogenized with a Tissue Lyser II system (Qiagen, Hilden, Germany), and total RNA was extracted from these tissue samples using TRIzol-A ${ }^{+}$Reagent (Tiangen, Beijing, China) according to the manufacturer's protocol. The One Step TB Green Prime Script PLUS RT-PCR Kit (TaKaRa, Japan) was used for q-RT-PCR quantification on the BIO-RAD iCycler Thermal Cycler. The detection primers used for mRNA profiling are shown in Table S1.

\section{Fluorescence confocal microscopy observation}

Local skin tissues from immunized mice were obtained and immediately frozen in liquid nitrogen. The tissue sections were embedded, sliced, fixed and then blocked using $5 \%$ bovine serum albumin (BSA). For detection of the viral antigen, the sections were sequentially incubated with a primary mouse anti-SARSCoV-2 spike antibody (SinoBiological Co., Ltd, China) and an AlexaFluor 647-conjugated goat anti-mouse IgG secondary antibody (Invitrogen, MA, USA). Dendritic cells (DCs) were detected with an anti-CD11c antibody (Abcam, Cambridge, UK) and Alexa Fluor ${ }^{\circledR} 488$ goat anti-rabbit IgG secondary antibody (Invitrogen). All cell nuclei were detected with DAPI. Fluorescence was visualized and analyzed using a confocal microscope (TCS SP2, Leica).

\section{Histopathological detection of mouse tissues in the challenge test}

The organs of experimental animals were fixed with $10 \%$ formalin, embedded in paraffin, sliced into $4-\mu \mathrm{m}$ sections and stained with hematoxylin and eosin (H\&E). Morphology was assessed with an inverted microscope (Nikon).

\section{q-RT-PCR assay for viral load measurement}

Total RNA was extracted from blood and tissue samples from experimental animals with TRIzol reagent (Tiangen, Beijing, China). q-RT-PCR was performed using a Novel Coronavirus (2019-nCoV) Nucleic Acid Isothermal Amplification Rapid Detection Kit (Chinese Center for Disease Control and Prevention, China) according to the protocol. The primers used for q-RT-PCR were selected to specifically amplify the $\mathrm{N}$ and ORF1ab sequences in the SARS-CoV-2 genome. The viral copy numbers of the samples were quantified from the standard (National Institute of Metrology, China).

\section{Statistical analysis}


Data are shown as the mean or geometric mean and standard deviation (SD) values. GraphPad Prism software (San Diego, CA, USA) was used for statistical analyses.

\section{Results}

\section{Antigenic identification of the recombinant K-S protein with 6 mutated sites and inactivated vaccine}

Based upon recently reported data on variant strains, an optimized sequence of the S1 protein with 6 mutated sites (N501Y, K417N, E484Q, L452R, P681R and D614G) found in the variants B.1.351, B.1.617.2 and B.1.1.7 was named K-S (Fig. 2a) $12,22,23,24$. The specific antigenicity of this recombinant protein was first investigated by immunoblotting with convalescent serum from confirmed COVID-19 patients in Wuhan and immune serum from vaccinated individuals in our clinical trial of the inactivated vaccine ${ }^{18}$. The results indicated that this protein was recognized by both sera (Fig. 2b), while the serum collected from rabbits immunized with this protein attached to $\mathrm{Al}(\mathrm{OH})_{3}$ adjuvant with a procedure involving three injections at intervals of 14 days was also capable of interacting with S protein with different mutated sites (Fig. 2c). These data confirmed the specific antigenicity of the K-S protein. The inactivated vaccine used in this study was developed by this laboratory, and its protective efficacy is being evaluated in a phase III clinical trial; this vaccine was produced through two technical steps of inactivation with formaldehyde and $\beta$-propiolactone to expose the viral $\mathrm{S}$ and $\mathrm{N}$ proteins. The $\mathrm{S}$ and $\mathrm{N}$ antigenicity of this inactivated vaccine was confirmed by immune-electron microscopy and a phase I and II clinical trial (Fig. 2d) 18,19 .

\section{Activation of the innate immune response in epithelial tissues inoculated with K-S protein or inactivated vaccine via the intradermal route}

Previous data from an immunological study of viral vaccines suggested that the intradermal vaccination strategy could not only reduce the amount of antigen required to induce immunity ${ }^{25}$ but also promote better antiviral immunity through activation of the innate immune response followed by the adaptive immune response 26,27 . In the current study, a licensed microneedle apparatus for intradermal injection enabled the injection of vaccine antigens into epithelial tissue at a depth of $0.6 \mathrm{~mm}^{28}$. Our observations suggested that the local skin tissue of mice inoculated with SARS-CoV-2 inactivated vaccines or K-S peptide antigens demonstrated more active dynamic alterations in the mRNA profile related to immuneregulatory signaling molecules than local muscle tissue, especially IFN-a, TNF-a, RANKL, BTLA, LIGHT, IKK $\beta, 4$ IBBL and interleukins as like IL-5, IL-9, IL-13, IL-25 and IL-33 (Fig. 3a). Further observation using fluorescence confocal microscopy suggested that the colocalization rate of antigen from the inactivated vaccine or K-S protein and dendritic cells in skin tissue was 2 to 3 times higher than that in muscle tissue post injection (Fig. 3b). These data suggested that the efficacy of antigens in activating the innate immune system in epithelial tissue is higher than that in muscle tissue, which further suggests that adaptive immunity induced by the innate response could be improved to elicit a stronger antibody response after intradermal immunization. Our neutralizing antibody assay indicated that all mice intradermally immunized with one dose of inactivated vaccine (30 U/dose) or K-S antigen (10 $\mu \mathrm{g} / \mathrm{dose})$ 
showed $100 \%$ seroconversion with GMTs of $20-30$, compared to $50 \%$ seroconversion with GMTs of 3-4 in mice intramuscularly immunized with one dose of inactivated vaccine or K-S antigen (Fig. 3c). All of these data confirmed the value of intradermal immunization with the SARS-CoV-2 vaccine antigen.

\section{Antibody response elicited by sequential immunization with the inactivated vaccine and K-S antigen via the intradermal route}

Based on the immunological observation of the SARS-CoV-2 inactivated vaccine and K-S antigen administered by intradermal immunization in animals and recently reported information about variant strains, our work aimed to increase the levels of neutralizing antibodies associated with specific recognition of antigens from variants. We designed an intradermal immunization strategy involving one or two doses of inactivated vaccine in two groups of $30 \mathrm{U}$ and 50U/dose and one boost with the K-S protein $(10 \mu \mathrm{g})$. Evaluation of this heterologous vaccine was performed in $\mathrm{C} 57$ mice, $\mathrm{ACE}^{+/+}$transgenic mice and rhesus macaques (Fig. 1a, b). First, neutralizing antibody assays indicated that the intradermal boost with the S1 protein with mutated sites was capable of eliciting higher neutralizing antibody levels than the inactivated vaccine in immunized mice, regardless of the antigen amount or number of vaccinations (Fig. 4a). In C57 mice subjected to observation of persistent immunity, the neutralizing antibody levels in injected animals by two dose of inactivated vaccine (50 U/dose) showed a upward trend from day 0 (28 days post the first immunization) to 14 (42 days post the first immunization) post boost immunization with $\mathrm{K}-\mathrm{S}$ than did those in mice immunized with $30 \mathrm{U} /$ dose, with a GMT of 88.44 to 322.54 and 70.20 to 222.86 , which was similar to the trend in mice immunized one time intradermally with $30 \mathrm{U}$ and $50 \mathrm{U}$ doses of the inactivated vaccine (Fig. 4a). ELISA antibody detection in these mice showed a similar trend (Fig. 4b). The same trends were observed in $\mathrm{ACE}^{+/+}$transgenic mice subjected to the viral challenge test (Fig.S2). Furthermore, the neutralizing antibody level was maintained until day 28 (56 days post the first immunization) and showed a slight decrease on day 56 (84 days post the first immunization) post K-S antigen boost after reaching GMTs of 430.54 -186.81 in C57 mice of MC-4 group (Fig. 4a). ELISA showed that antibody levels exhibited similar alterations during the observation period, in which the GMTs of S antibody reached to 8542.97-11942.8 in MC-4 group (Fig. 4b). The neutralizing antibody assay in immunized macaques also indicated that one intradermal immunization with $30 \mathrm{U}$ or $50 \mathrm{U}$ of inactivated vaccine and one boost of K-S antigen was capable of eliciting neutralizing antibodies, with GMTs of 608.87 and 1024 in subgroups RE-1 and RE-2 on day 14 post boost immunization (42 days post the first immunization); the upward trend was maintained for one and a half months (Fig. 4c). Interestingly, two intradermal immunizations with $30 \mathrm{U}$ or $50 \mathrm{U}$ of inactivated vaccine and one boost of KS antigen in subgroups RF-1 and RF-2 led to GMTs of neutralizing antibody, with the same GMTs of 608.87, respectively, in these two subgroups; these titers were maintained until day 56 (84 days post the first immunization) post boost immunization (Fig. 4c). ELISA also showed that antibody levels exhibited similar alterations during the observation period with the GMT peake of 25600 and 21526.9 in RF-1 and RF-2 group (Fig. 4d). Importantly, a cross-neutralization assay showed that the immune sera induced in subgroups RE and RF enabled neutralization of three strains, Wuhan, B.1.351 and B.1.617.2 with similar titers (Fig. 4e). These data confirmed the immunological efficacy of our heterologous vaccine strategy. 


\section{Specific T cell responses against antigens from variants were elicited in animals immunized with the heterologous vaccine strategy}

In our previous work on SARS-CoV-2 inactivated vaccines, memory T cell responses against the $\mathrm{S}$ and $\mathrm{N}$ antigens of the Wuhan strain were identified in vaccinated animals and humans ${ }^{19,29}$. Here, we aimed to investigate whether the immune memory induced by intradermal immunization with the inactivated vaccine could be enhanced for distinct recognition of variant antigens after boosting with the K-S antigen with mutated sites. An IFN-y ELISPOT assay with variant antigens, including RBD peptides with the $417 \mathrm{~N}$, 452R, 484Q, 501Y and 452R + 484Q mutations, was used in the current work and showed that specific T cell responses against RBD peptides with 5 variants were significantly stronger in mice immunized with the inactivated vaccine in group MC on day 28 after boosting with the K-S antigen than in mice in the adjuvant control (MD-2) and K-S antigen alone control groups (MD-1) (Fig. 5a), with no significant differences according to antigen amount and number of immunizations (Fig. 5a). The T cell response against the $\mathrm{N}$ protein in group $\mathrm{MC}$ also showed a strong upward trend (Fig. $5 \mathrm{~b}$ ). The ELISPOT results for macaques suggested a dynamic upward trend of $T$ cell responses against the 5 variants compared to the control on day 28 post boosting with the K-S antigen, which showed the dose-effect relationship in RE group (Fig. 5c). The $\mathrm{T}$ cell response against the $\mathrm{N}$ protein in these macaques also presented a similar trend (Fig. 5d). Together with the antibody response data, these results suggested the feasibility of the heterologous strategy using the vaccine to prevent infection caused by variants through induction of systemic immunity with a high titer of neutralizing antibody and specific $T$ cell recognition.

\section{Evaluation of the immunological protective efficacy of the heterologous vaccine strategy in $\mathrm{ACE}^{+/+}$transgenic mice after viral challenge}

Although our data on antibody and T cell responses were confident, the clinical protective efficacy of this heterologous vaccine needed further evaluation in the current study. A viral challenge test with the B.1.617.2 strain was performed in immunized $\mathrm{ACE}^{+/+}$transgenic mice from groups $\mathrm{MA}$ and $\mathrm{MB}$ according to the schedule in Fig. $1 \mathrm{a}$. Virus $\left(10^{3} \mathrm{CCID}_{50}\right.$ /each) was inoculated by a spray administered via the nasal route. Clinical observation of all challenged mice within 11 days post infection suggested that all adjuvant control (MB-2) and K-S antigen control (MB-1) mice and a few of MA-1 and MA-3 mice presented manifestations including an arched back, shedding of hair and body weight loss to varying degrees (Fig. 6a), and some mice even died from days 5 to 8; in contrast, the MA-2 mice, which were immunized intradermally with one inactivated vaccine at $50 \mathrm{U} /$ dose followed by a boost with the K-S antigen, were healthy, except for one mouse that died. The mice in M-4 administrated intradermally with two inactivated vaccines at $50 \mathrm{U} /$ dose followed by a boost with the K-S antigen were healthy during the observation period, except for one mouse that died when bitten by other mice (Fig. 6b). Detection about these died mice suggested high viral proliferation in the tissues of lung and brain of animals, especially in those of MB1 and MB2 groups (Fig. 6c). Further monitoring of the viral loads in survived mice indicated that the mice in subgroups MA-2 and MA-4 presented only in the range of $1.73-169.29 \mathrm{copies} / \mu \mathrm{l}$ and 0.38-49.64 copies/ $\mu$ in nasal and throat respectively on days 5 and 6 , the most of them were close to 
the detection threshold ( 5 copies/ $\mu \mathrm{l})$, compared to the obvious upward trend in the other subgroups, which reached to $25.58-526.36 \mathrm{copies} / \mu \mathrm{l}$ and $11.52-103.71 \mathrm{copies} / \mu \mathrm{l}$ (Fig. 6d). Further detection of viral loads in various organs and tissues of sacrificed mice on days 3, 7 and 11 confirmed that the mice in MA2 and MA-4 were protected by the immunity elicited by the heterologous vaccine with two intradermal immunizations of inactivated vaccine ( $50 \mathrm{U} /$ dose) followed by a boost with the K-S antigen in the challenge test with strain B.1.617.2 (Fig. 6e). The histopathological analysis confirmed this conclusion by comparing the pathological injuries in various organs/tissues, especially the lung tissues, between MA-2 or MA-4 and the other subgroups (Table 1; Fig. 6f). These data strongly support the conclusion that the both strategies of " $1+1$ " and " $2+1$ " intradermal immunization with the inactivated vaccine and K-S antigen is capable of leading to effective immunity against variants of SARS-CoV-2, with high levels of neutralizing antibodies and specific $T$ cell recognition ability. 
Table 1

Histopathological analysis of various tissues or organs in $\mathrm{ACE}^{+/+}$transgenic mice immunized with the heterologous vaccine administered intradermally after B.1.617.2 strain challenge.

\begin{tabular}{|c|c|c|c|c|}
\hline \multirow[t]{2}{*}{ Organ } & \multirow[t]{2}{*}{ Group } & \multicolumn{3}{|c|}{ Day post infection } \\
\hline & & 3 & 7 & 11 \\
\hline \multirow[t]{6}{*}{ Brain } & MB-1 & - & / & / \\
\hline & MB-2 & - & / & / \\
\hline & MA-1 & - & $-\bigotimes+$ & $-\nabla+$ \\
\hline & MA-2 & - & $-\unrhd \pm$ & - \\
\hline & MA-3 & - & - & $-\nabla+$ \\
\hline & MA-4 & - & - & - \\
\hline \multirow[t]{6}{*}{ Heart } & MB-1 & - & I & I \\
\hline & MB-2 & $-\rrbracket++$ & I & I \\
\hline & MA-1 & - & - & - \\
\hline & MA-2 & $-\llbracket \pm$ & - & - \\
\hline & MA-3 & - & - & - \\
\hline & MA-4 & - & - & - \\
\hline \multirow[t]{6}{*}{ Liver } & MB-1 & + & I & I \\
\hline & MB-2 & + & I & I \\
\hline & MA-1 & $-\nabla \pm$ & $-\rrbracket \pm$ & $-\square \pm$ \\
\hline & MA-2 & $\pm \rrbracket+$ & $\pm \rrbracket+$ & $\pm \rrbracket+$ \\
\hline & MA-3 & $-\nabla+$ & $-\bigotimes \pm$ & $\pm \rrbracket+$ \\
\hline & MA-4 & $-\nabla \pm$ & $-\mathbb{+}+$ & $-\rrbracket \pm$ \\
\hline \multirow[t]{6}{*}{ Spleen } & MB-1 & - & / & / \\
\hline & MB-2 & - & I & / \\
\hline & MA-1 & - & - & - \\
\hline & MA-2 & - & - & - \\
\hline & MA-3 & - & - & - \\
\hline & MA-4 & - & - & - \\
\hline
\end{tabular}




\begin{tabular}{|c|c|c|c|c|}
\hline \multirow{2}{*}{$\begin{array}{l}\text { Organ } \\
\text { Kidney }\end{array}$} & \multirow{2}{*}{$\begin{array}{l}\text { Group } \\
\text { MB-1 }\end{array}$} & \multicolumn{3}{|c|}{ Day post infection } \\
\hline & & - & I & I \\
\hline & MB-2 & - & I & I \\
\hline & MA-1 & - & - & - \\
\hline & MA-2 & - & - & - \\
\hline & MA-3 & $-\nabla \pm$ & - & - \\
\hline & MA-4 & - & - & - \\
\hline \multirow[t]{6}{*}{ Gnitals } & MB-1 & - & I & I \\
\hline & MB-2 & - & I & I \\
\hline & MA-1 & - & - & - \\
\hline & MA-2 & - & - & - \\
\hline & MA-3 & - & - & - \\
\hline & $\mathrm{MA}-4$ & - & - & - \\
\hline
\end{tabular}

\section{Discussion}

The recently emerged variants of SARS-CoV-2 have led to general concern from the public and researchers, although the global pandemic of COVID-19 has been partially controlled in most areas in the world 2,3,4,5. Faced with this event and other problems, such as the rapid drop in neutralizing antibodies in convalescent patients 9,10 , general concerns about the persistence of neutralizing antibodies in vaccinated individuals and a lack of understanding of the immunological characteristics of this virus, it is important to investigate new generations of effective vaccines against these variants building upon various licensed vaccines administered to more than one billion people worldwide ${ }^{1,30}$. Here, we propose a strategy of intradermal immunization with a heterologous vaccine composed of one or two doses of inactivated vaccine and a boost with the $\mathrm{S} 1$ protein with mutations (K-S), which was designed to increase the immune efficacy of licensed vaccines by increasing neutralizing antibody titers and promoting specific $T$ cell responses against variant antigens. First, our study suggested that only $1 / 5$ to $1 / 3$ of the antigen previously used in the inactivated vaccine followed by a boost with the K-S antigen ( $10 \mu \mathrm{g} / \mathrm{dose})$ in mice and macaques was capable of augmenting neutralizing antibody titers to 5-10 times those observed in individuals vaccinated with two intramuscular injections of the inactivated vaccine. In mice, this upward trend of antibody titers showed positive relationship to the amount of antigen or the number of immunizations with the inactivated vaccine, and in macaques, more obvious relationship between these parameters presented. These data are supportive to the conclusion that this strategy of K-S boost 
via intradermal route enables the enhanced induction of an immune response in both animals. Second, mice or macaques immunized with this heterologous vaccine showed stronger specific $T$ cell responses against 5 variants of RBD peptides, with similar reactivity levels associated with stronger responsive spots against the $\mathrm{N}$ antigen. These data implied that a higher titer of neutralizing antibody might depend primarily upon systemic immunity, which was indicated by the sensitive and specific antigenic recognition ability of memory $T$ cells against variants of $S$ antigen and $N$ antigen. Third, the viral challenge test with the B.1.617.2 strain affirmed that both schedules of " $1+1$ " and " $2+1$ " administration ensured a clinical protective effect against this strain through the data of significant low viral load in tissues of immunized mice and little of slight inflammatory infiltration in lung tissue and brain compared to the controls. However, the antigen amount of inactivated vaccine is more powful factor than the number of immunization for this immunological protective effect. All of these results further suggested not only the feasibility of our strategy for the development of heterologous vaccines against new variants but also a technical pathway to enhance the anamnestic immune response and to elicit specific recognition of variants by $T$ cells in the immunized population, especially those vaccinated with inactivated vaccines,. This heterologous vaccine has been evaluated for its safety and was identified as safe. Significantly, this work also provided important supportive evidence for intradermal immunization, which was recommended for the inactivated polio vaccine by the WHO because of the reduced amounts of antigen used in children globally ${ }^{31}$. Our work suggests that this strategy of intradermal immunization can not only increase the supply of vaccines to meet global demand for controlling COVID-19 pandemic but also imply a possible mechanism by which boost with the $\mathrm{S} 1$ protein enables the induction of an immune response to inactivated vaccines via effective recall of immune memory. It should be mentioned that this approach will be very valuable for the large population vaccinated with inactivated vaccines to improve their immunity against SARS-CoV-2 variants by increasing the levels of neutralizing antibodies and promoting specific recognition of antigens from variants. If this is the case, more studies on genetic prediction of variation trends in the S protein of SARS-CoV-2 and effective vaccine strategies for the antigen boost, such as peptide or mRNA approaches, will be of interest.

\section{Declarations}

\section{Acknowledgments}

This work was supported by the National Key R\&D Program of China (2020YFC0849700 and 2020YFC0860600), the Major Science and Technology Special Projects of Yunnan Province (202101AS070053, 202102AA310043 and 202003AC100003), and the Program of Chinese Academy of Medicine Science (2020HY320001).

\section{Conflicts of interest}

The sponsor of the study played no role in the study design, data and sample collection, data processing, or report writing. The corresponding author had full access to all the data generated by the study and takes full responsibility for the final submission for publication. 


\section{References}

1. Johns_Hopkins_University. COVID-19 Dashboard by the Center for Systems Science and Engineering (CSSE) at Johns Hopkins University (JHU). Preprint at https://www.arcgis.com/apps/dashboards/bda7594740fd40299423467b48e9ecf6 (2020).

2. Zhou D, et al. Evidence of escape of SARS-CoV-2 variant B.1.351 from natural and vaccine-induced sera. Cel/ 184, 2348-2361.e2346 (2021).

3. Weisblum Y, et al. Escape from neutralizing antibodies by SARS-CoV-2 spike protein variants. Elife 9 , (2020).

4. Harvey WT, et al. SARS-CoV-2 variants, spike mutations and immune escape. Nat Rev Microbio/ 19, 409-424 (2021).

5. Plante JA, Mitchell BM, Plante KS, Debbink K, Weaver SC, Menachery VD. The variant gambit: COVID19's next move. Cell Host Microbe 29, 508-515 (2021).

6. BioValley. Overview of global SARS-COV-2 vaccine development. Preprint at https://mp.weixin.qq.com/s/TCg6-PLBMS74eQ6rAsoszg (2021).

7. Rogers TF, et al. Isolation of potent SARS-CoV-2 neutralizing antibodies and protection from disease in a small animal model. Science 369, 956-963 (2020).

8. Mendoza P, Lorenzi JCC, Gaebler C. COVID-19 antibody development fueled by HIV-1 broadly neutralizing antibody research. Curr Opin HIV AIDS 16, 25-35 (2021).

9. Seow J, et al. Longitudinal observation and decline of neutralizing antibody responses in the three months following SARS-CoV-2 infection in humans. Nat Microbio/ 5, 1598-1607 (2020).

10. Pradenas $\mathrm{E}$, et al. Stable neutralizing antibody levels 6 months after mild and severe COVID-19 episodes. Med (N Y) 2, 313-320.e314 (2021).

11. Liao $\mathrm{Y}$, et al. Intensified antibody response elicited by boost suggests immune memory in individuals administered two doses of SARS-CoV-2 inactivated vaccine. Emerg Microbes Infect 10, 1112-1115 (2021).

12. Wang GL, et al. Susceptibility of Circulating SARS-CoV-2 Variants to Neutralization. N Engl J Med 384, 2354-2356 (2021).

13. Madhi SA, et al. Efficacy of the ChAdOx1 nCoV-19 Covid-19 Vaccine against the B.1.351 Variant. $N$ Engl J Med 384, 1885-1898 (2021).

14. Wang P, et al. Antibody resistance of SARS-CoV-2 variants B.1.351 and B.1.1.7. Nature 593, 130-135 (2021).

15. Garcia-Beltran WF, et al. Multiple SARS-CoV-2 variants escape neutralization by vaccine-induced humoral immunity. Cel/ 184, 2372-2383.e2379 (2021).

16. Cantón R, et al. New variants of SARS-CoV-2. Rev Esp Quimioter, (2021).

17. Quinonez E, Vahed M, Hashemi Shahraki A, Mirsaeidi M. Structural Analysis of the Novel Variants of SARS-CoV-2 and Forecasting in North America. Viruses 13, (2021). 
18. Che Y, et al. Randomized, double-blinded and placebo-controlled phase II trial of an inactivated SARSCoV-2 vaccine in healthy adults. Clin Infect Dis, (2020).

19. Pu J, et al. The safety and immunogenicity of an inactivated SARS-CoV-2 vaccine in Chinese adults aged 18-59 years: A phase I randomized, double-blinded, controlled trial. Vaccine 39, 2746-2754 (2021).

20. Li R. Transient transfection of $\mathrm{CHO}$ cells using linear polyethylenimine is a simple and effective means of producing rainbow trout recombinant IFN-y protein. Cytotechnology 67, 987-993 (2015).

21. Zhang $X$, et al. Immune mechanisms induced by an HSV-1 mutant strain: Discrepancy analysis of the immune system gene profile in comparison with a wild-type strain. Vaccine 36, 2394-2402 (2018).

22. Ostrov DA. Structural Consequences of Variation in SARS-CoV-2 B.1.1.7. J Cell Immuno/ 3, 103-108 (2021).

23. Wang R, Chen J, Gao K, Wei GW. Vaccine-escape and fast-growing mutations in the United Kingdom, the United States, Singapore, Spain, India, and other COVID-19-devastated countries. Genomics 113, 2158-2170 (2021).

24. Frazier L, Lubinski B, Tang T, Daniel S, Jaimes JA, Whittaker G. Spike protein cleavage-activation mediated by the SARS-CoV-2 P681R mutation: a case-study from its first appearance in variant of interest (VOI) A.23.1 identified in Uganda. bioRxiv, (2021).

25. Schnyder JL, et al. Comparison of equivalent fractional vaccine doses delivered by intradermal and intramuscular or subcutaneous routes: A systematic review. Travel Med Infect Dis 41, 102007 (2021).

26. Criscuolo E, Caputo V, Diotti RA, Sautto GA, Kirchenbaum GA, Clementi N. Alternative Methods of Vaccine Delivery: An Overview of Edible and Intradermal Vaccines. J Immunol Res 2019, 8303648 (2019).

27. Hunsaker BD, Perino LJ. Efficacy of intradermal vaccination. Vet Immunol Immunopathol 79, 1-13 (2001).

28. Fan S, et al. Study of integrated protective immunity induced in rhesus macaques by the intradermal administration of a bivalent EV71-CA16 inactivated vaccine. Vaccine 38, 2034-2044 (2020).

29. Chen H, Xie Z, Long R, Fan S, Li Q. A valid protective immune response elicited in rhesus macaques by an inactivated vaccine is capable of defending against SARS-CoV-2 infection. (2020).

30. CNBC. China has administered more than 1 billion doses of its Covid-19 vaccines. Preprint at https://www.cnbc.com/2021/06/21/china-covid-19-vaccines-more-than-1-billion-dosesadministered.html (2021).

31. Nelson KS, Janssen JM, Troy SB, Maldonado Y. Intradermal fractional dose inactivated polio vaccine: a review of the literature. Vaccine $30,121-125$ (2012).

\section{Figures}


(a)

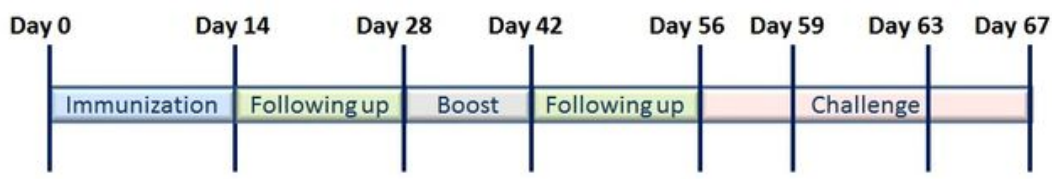

\begin{tabular}{|c|c|c|c|c|c|c|c|c|c|}
\hline \multirow{4}{*}{ (ח) } & {$[$ MA-1 } & 1. $I D(300)$ & & $1 D(K-S)$ & (2) & 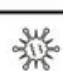 & $\mathbb{\$}$ & $\mathbb{4}$ & $\mathbb{W}$ \\
\hline & $M A-2$ & $\mathrm{ID}(50 \mathrm{U})$ & & F) $I D(K-S)$ & 20 & 舜 & $\mathbb{W}$ & $\sqrt{5}$ & $\mathbb{W}$ \\
\hline & MA-3 & $\mathrm{ID}(30 \mathrm{U})$ & $1 \mathrm{D}(30 \mathrm{U})$ & (7) $I D(K-S)$ & (2) & 筑 & $\Uparrow$ & $\widehat{t a}$ & \\
\hline & MA-4 & $1 D(500)$ & $10(500)$ & F. $I D(K-S)$ & 라 & औ誉 & $\mathbb{W}$ & $\mathbb{T}$ & TI \\
\hline \multirow{2}{*}{ 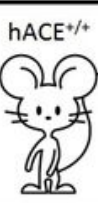 } & [MB-1 & ID(PBS) & & (7) $I D(K-S)$ & 20 & 舜 & $\mathbb{\$}$ & of & I \\
\hline & L MB-2 & $\mathrm{ID}(\mathrm{Adj})$ & $\operatorname{ID}(\mathrm{Adj})$ & (2) & 0 & औ兴 & $\Uparrow$ & 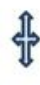 & 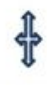 \\
\hline
\end{tabular}

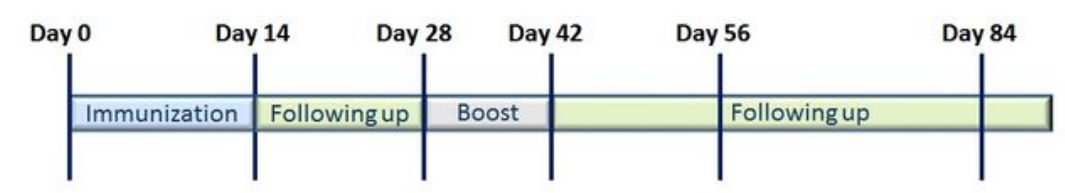

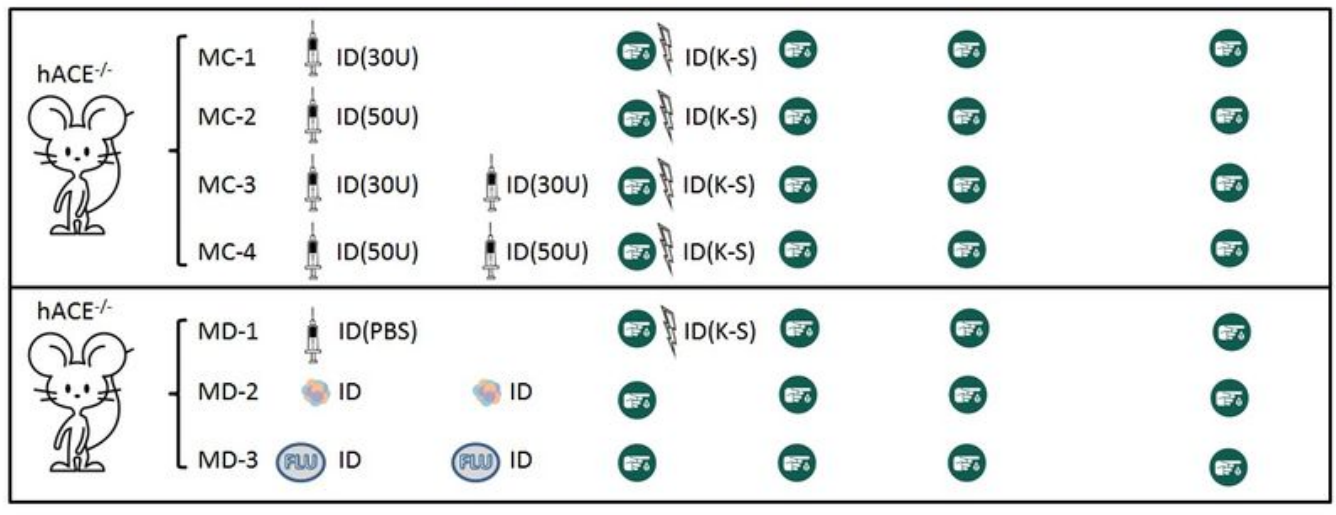

(b)

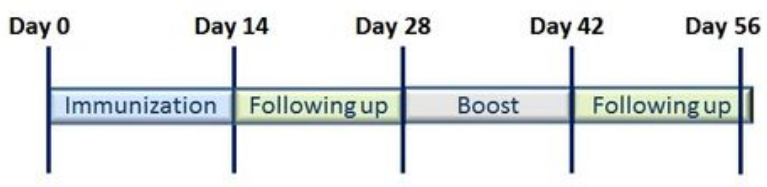

\begin{tabular}{|c|c|c|c|c|c|}
\hline $\begin{array}{l}\because \theta^{2} \\
\text { stob? }\end{array}$ & {$\left[\begin{array}{l:l}\mathrm{RE}-1 & \mathrm{ID}(30 \mathrm{U}) \\
\mathrm{RE}-2 & \mathrm{ID}(50 \mathrm{U})\end{array}\right.$} & & $\begin{array}{l}\text {. } \\
I D(K-S)\end{array}$ & 라 & 6 \\
\hline & {$[\mathrm{RF}-1) \mathrm{ID}(30 \mathrm{U})$} & $\frac{1 D}{2}(30 U)$ & D. $1 D(K-S)$ & (2) & 라 \\
\hline dtol? & $\mathrm{RF}-2 \mathrm{ID}(50 \mathrm{OU})$ & ID(5OU) & - $1 D(K-S)$ & (7) & (7) \\
\hline
\end{tabular}

\section{Figure 1}

Design of animal immunization schedule and viral challenge. (a) Mouse immunity and challenge experiment. ACE+/+ transgenic mice (MA and MB group) and ACE-/- mice (MC and MD group) were included in this experiment. The mice were intradermally immunized (ID) with different doses (30 U or 50 U) of inactivated SARS-CoV-2 vaccine, PBS, adjuvant (Adj) and inactivated influenza vaccine through different procedures (one injection or two injections with an interval of 14 days). Some mice were 
boosted with the $\mathrm{K}-\mathrm{S}$ antigen ( $10 \mu \mathrm{g} / \mathrm{dose})$. Blood samples were obtained on days 28 and 42 after the first immunization in MA and MB group, on days 28, 42, 56 and 84 after the first immunization in MC and MD group for antibody assays. The viral challenge was performed on day 56 after the first immunization in MA and MB group. On days 3, 7 and 11, three mice in each group of MA and MB group were euthanized for viral load measurement and pathological observation. (b) Rhesus macaque immunity experiment. The macaques were intradermally immunized (ID) with different doses (30 U or $50 \mathrm{U}$ ) of inactivated SARS-CoV-2 vaccine through different procedures (one injection or two injections with an interval of 14 days). All macaques were boosted with the K-S antigen $(10 \mu \mathrm{g} / \mathrm{dose})$ on day 28 after the first immunization. Blood samples were obtained on days 28, 42 and 56 after the first immunization for antibody assays.

\section{(a) \\ K417N L452R E484Q \\ N501Y D614G P681R}

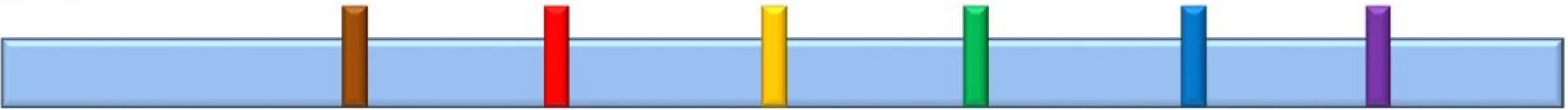

(b)

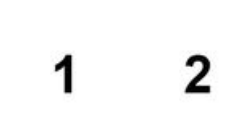

Conv

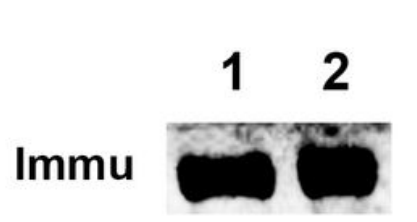

(c)

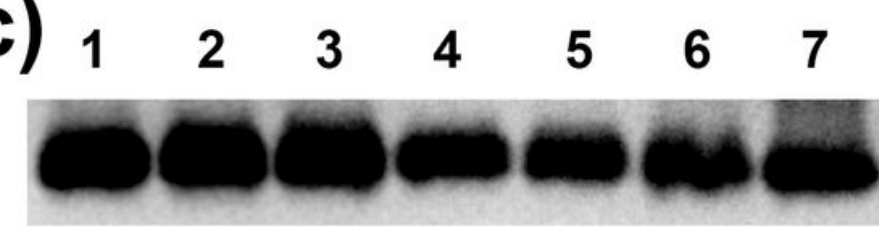

(d)
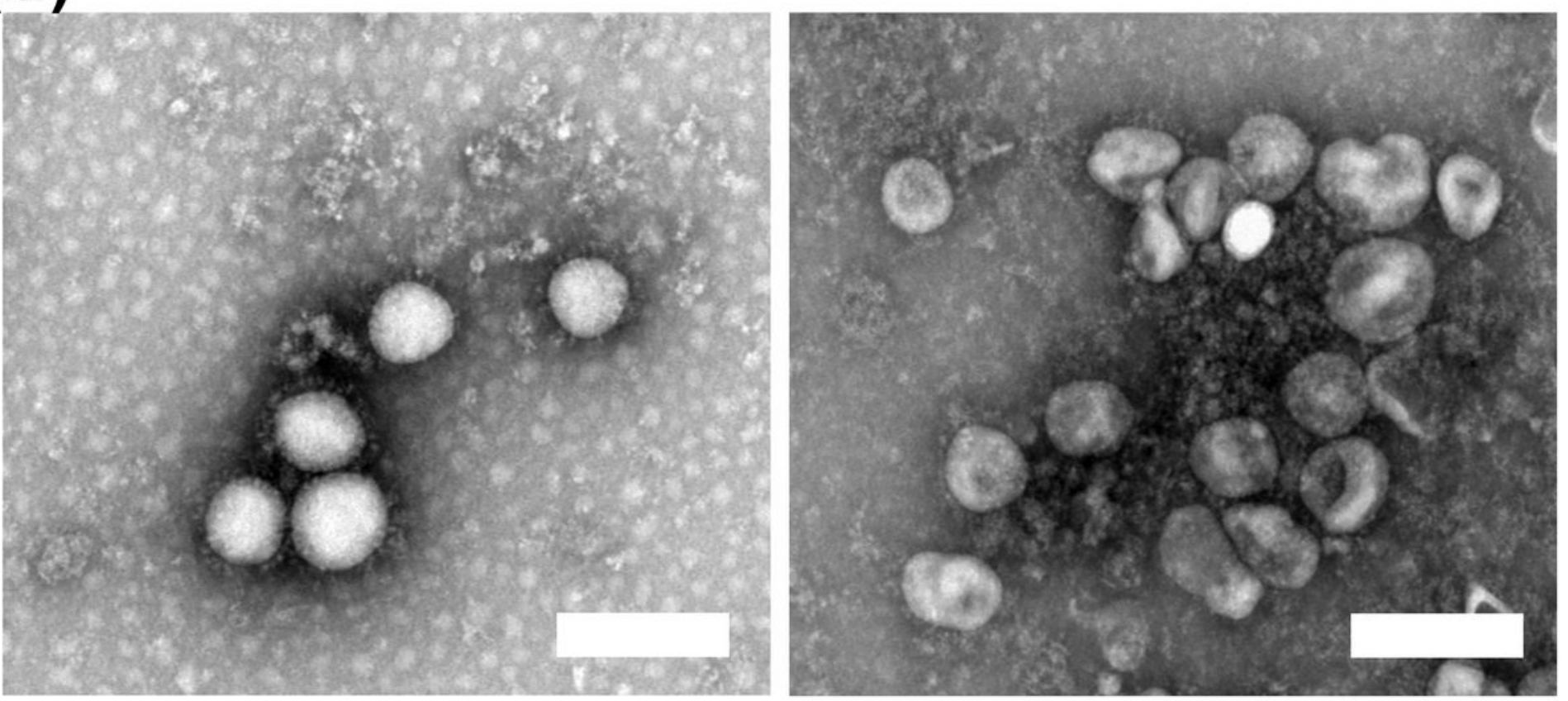

Figure 2

Immunological characterization of the recombinant K-S S1 peptide and inactivated vaccine. (a) An optimized sequence of the S1 protein (K-S) with 6 mutated sites (N501Y, K417N, E484Q, L452R, P681R and D614G). (b) K-S protein was recognized by both convalescent serum from confirmed COVID-19 
patients (Conv) and immune serum (Immu) from vaccinated individuals in a clinical trial. 1, S1 recombinant protein; 2 , K-S protein. (c) The serum from rabbits immunized with the K-S protein recognized the single-point mutation RBD protein and the unmutated RBD protein. 1, K417N; 2, L452R; 3, E484Q; 4, N501Y; 5,N439K; 6, A520V; 7, Spike RBD protein. (d) Electron micrograph of S/N particles. The interaction of inactivated SARS-CoV-2 antigens subjected to HCHO-BPL treatment with anti-S (left) and anti-N (right) antibodies. The inactivated viral antigens subjected to treatment with HCHO-BPL were coincubated with the anti-S or anti-N antibody for 2 hours at $37^{\circ} \mathrm{C}$ in PBS buffer and observed with an electron microscope (25000X). Bar, $200 \mathrm{~nm}$. 
(a)

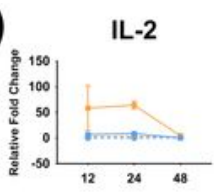

IL-9

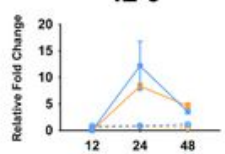

IFN- $\alpha$
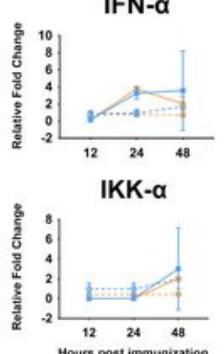

IL-4

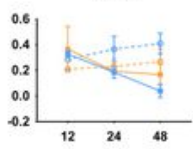

IL-13

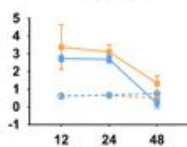

IFN- $\beta$

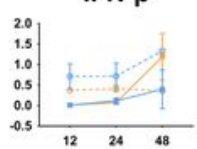

IKK- $\beta$

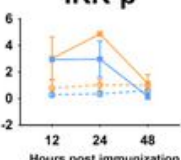

IL-5

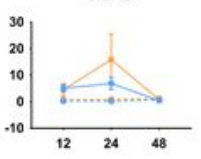

IL-25

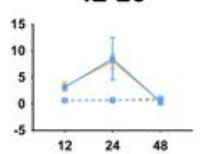

TNF- $\alpha$

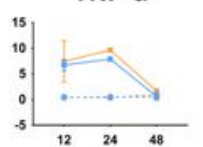

LIGHT

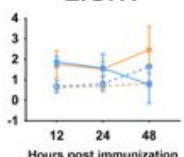

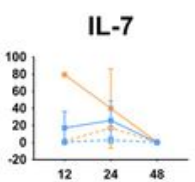

IL-33

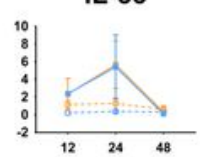

BTLA

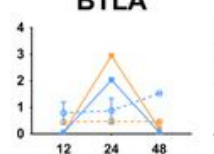

TLIA

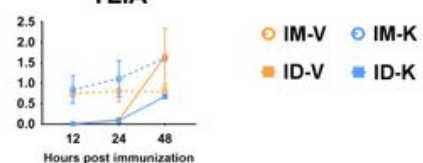

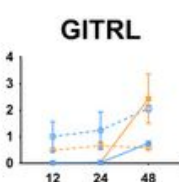

RANKL

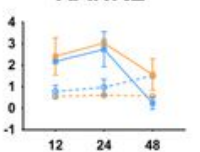

4IBBL
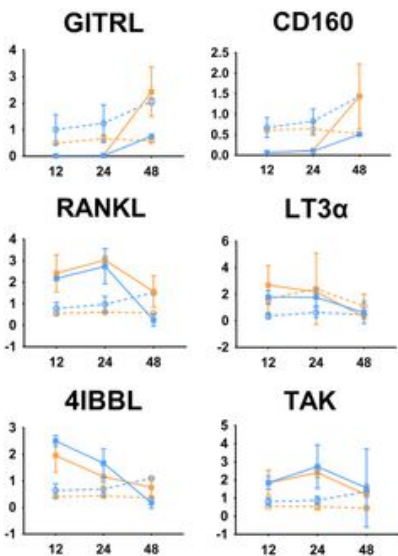

LT3 $\alpha$

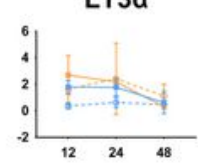

(b)
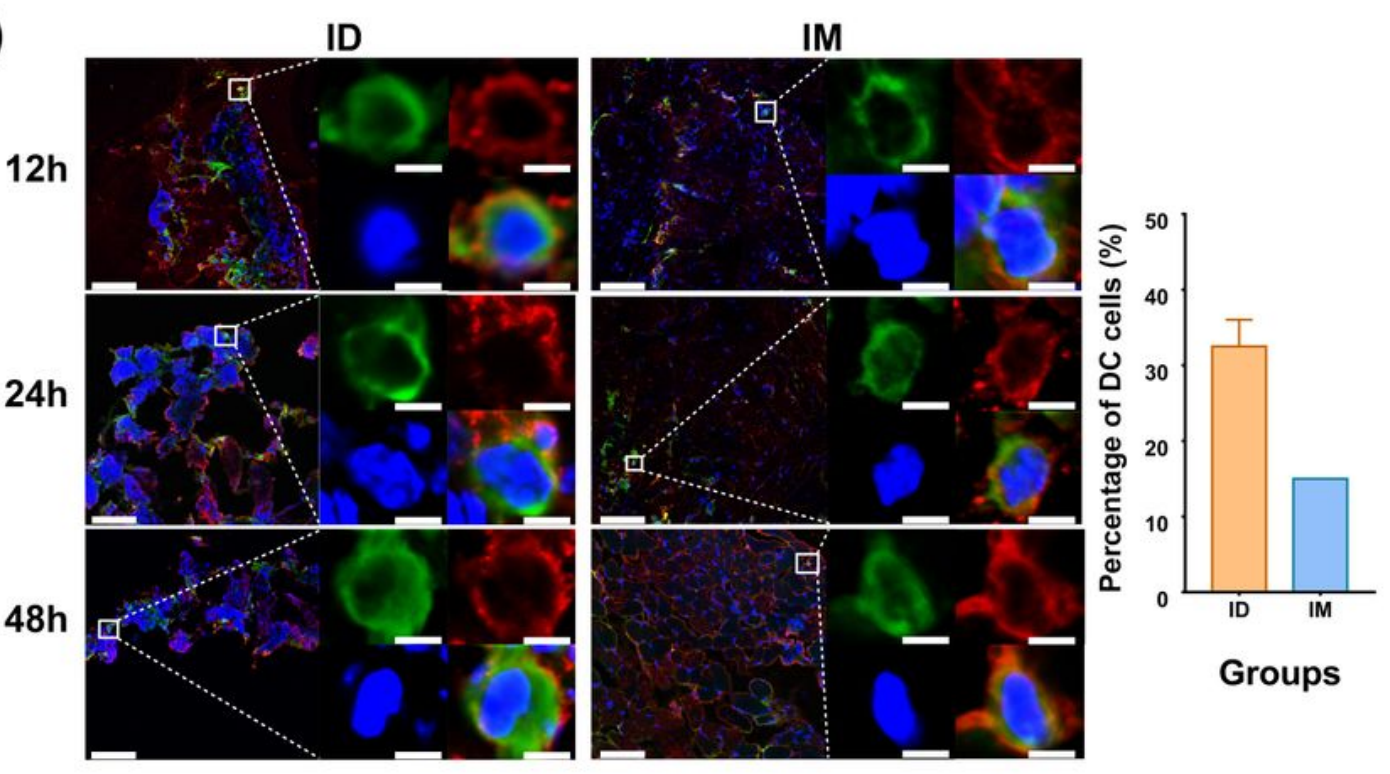

(c)

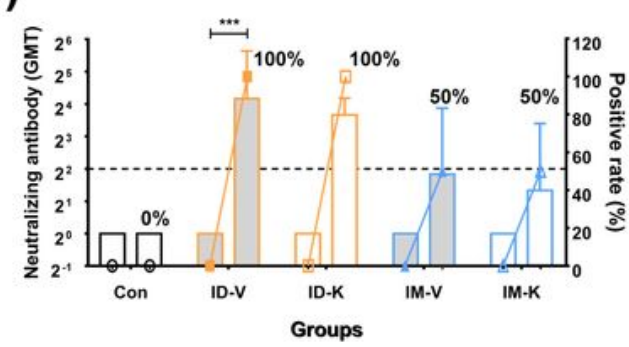

$\square$ Con

ए ID-V

$\square$ ID-K

$\square$ IM-V $\quad \square$ IM-K

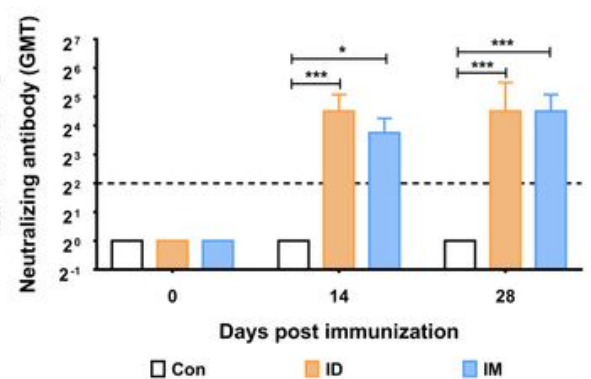

\section{Figure 3}

More powerful immunity is elicited by viral antigen via intradermal immunization than via intramuscular immunization. (a) Dynamic alteration of the mRNA profile related to immune-regulatory signaling molecules in the local skin tissue elicited by the SARS-CoV-2 inactivated vaccine or the K-S peptide antigen via the intradermal or intramuscular route. (b) The colocalization of viral antigen and dendritic cells in skin tissue elicited by the SARS-CoV-2 inactivated vaccine or K-S peptide antigen via the 
intradermal or intramuscular route. Nuclear staining (DAPI), viral antigen (red) and dendritic cells (green). Bar, $6 \mu \mathrm{m}$. The bar graph (right) shows the statistical analysis of colocalization with viral antigen and DC cells at $24 \mathrm{hr}$ after immunization. The percentage of colocalized cells in the total DC cells was based on observation of 60 fields. (c) Neutralizing antibodies induced by the SARS-CoV-2 inactivated vaccine or K$S$ peptide antigen via the intradermal or intramuscular route in mice (left) and monkeys (right). Live viral strain is KMS-2 (Wuhan strain). The positive rate was shown up the bar graph in mice experiment. *, $p<0.05$, $\star \star \star, ~ p<0.001$ versus before immunization (in mice) or control group (in monkey).

(a)

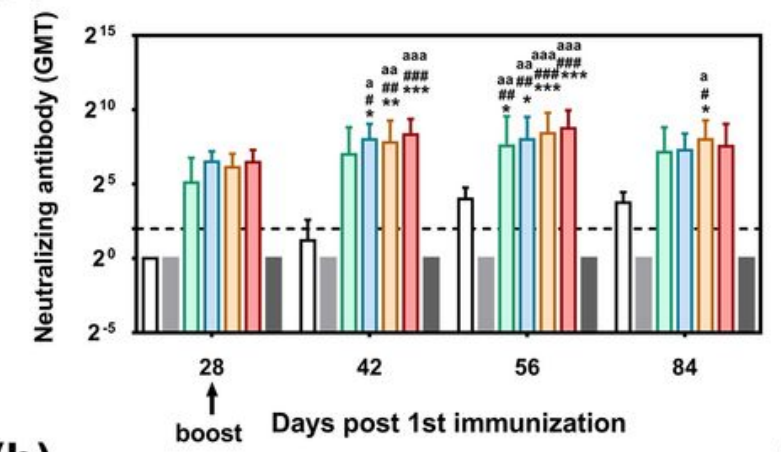

(b)
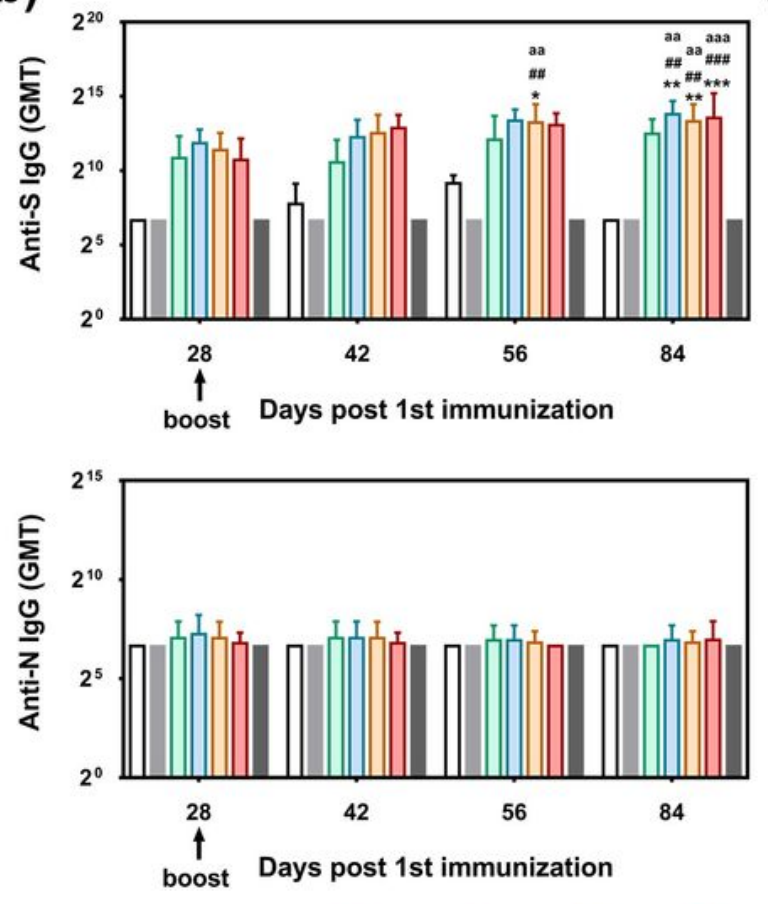

$\square$ MD-1 $\square$ MD-2 चMD-3 $\square$ MC-1 $\square$ MC-2 $\square$ MC-3 $\square$ MC-4

(e)

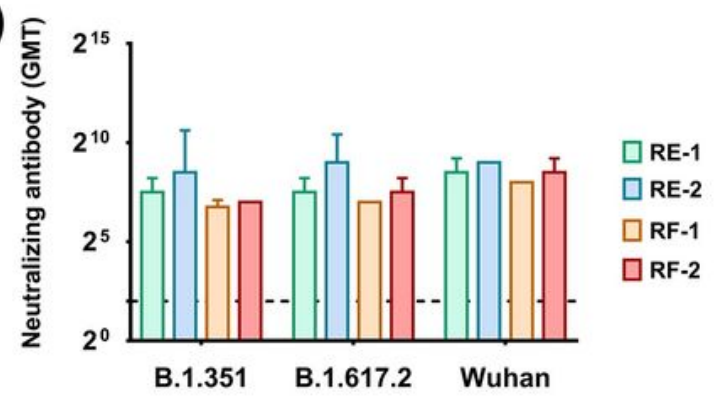

(c)

(d)
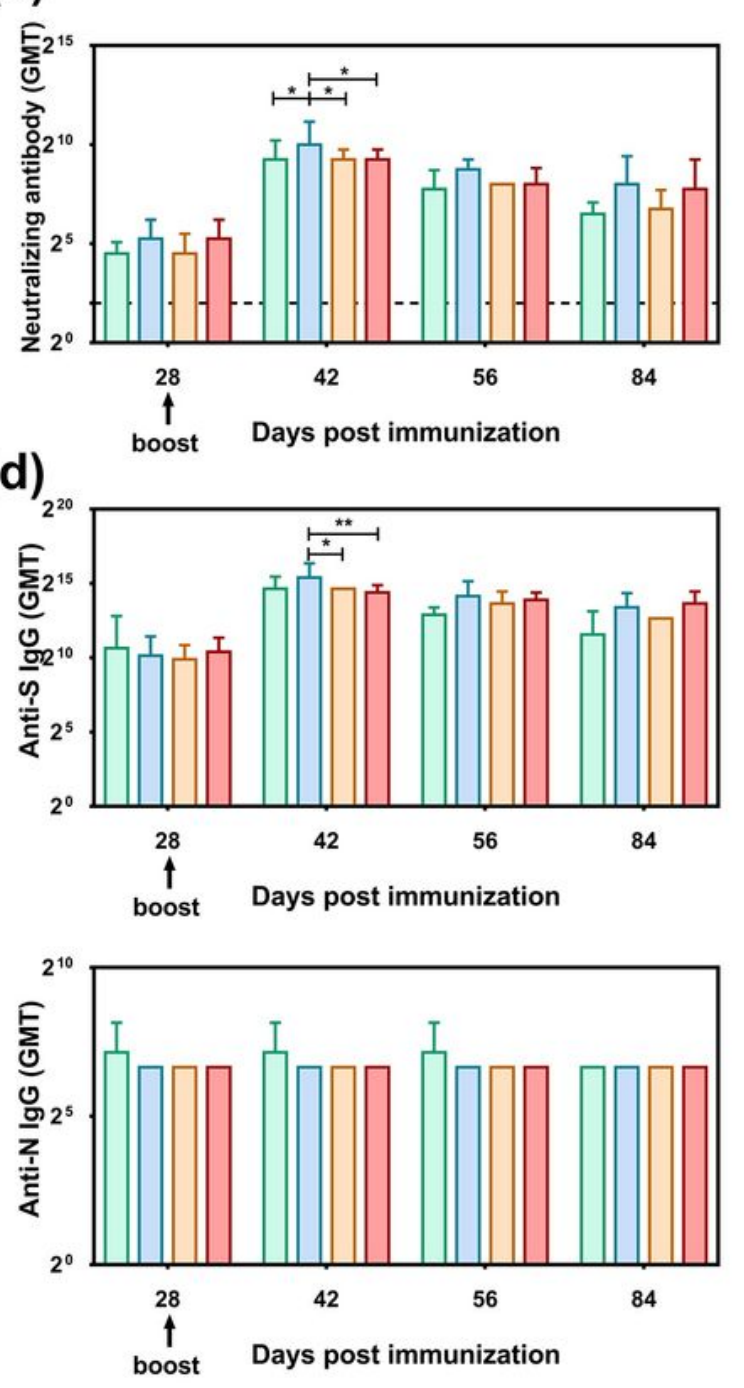

$\square$ RE-1 $\square R E-2 \quad \square R F-1 \quad \square R F-2$

Groups 


\section{Figure 4}

The heterologous vaccine strategy using intradermal immunization enables the induction of high levels of NAb against various variant strains. (a) Neutralizing antibodies recalled by boosting with the K-S protein in mice immunized with the inactivated vaccine. Live viral strain is KMS-2 (Wuhan strain). (b) The level of anti-S and anti-N antibodies after boosting with the K-S protein in mice immunized with the inactivated vaccine. *, $p<0.05 ; * \star, p<0.01$; $* \star * ; p<0.001$ versus MD-1 group. \#, $p<0.05 ; \# \#, p<0.01 ; \# \# \#$, $p<0.001$ versus MD-2 group. a, $p<0.05$; aa, $p<0.01$; aaa, $p<0.001$ versus MD-3 group. (c) The level of neutralizing antibodies induced by the inactivated vaccine and K-S protein in macaques. Live viral strain is KMS-2 (Wuhan strain). (d) The level of ELISA antibodies induced by the inactivated vaccine and K-S protein in macaques. (e) Cross-neutralization ability of the antibodies induced by the inactivated vaccine and K-S protein in macaques in vitro. The blood samples were obtained on day 84 afther the first immunization. Three live strains: B.1.351, B.1.617.2, Wuhan. *, $p<0.05$; **, $p<0.01$.

(a)

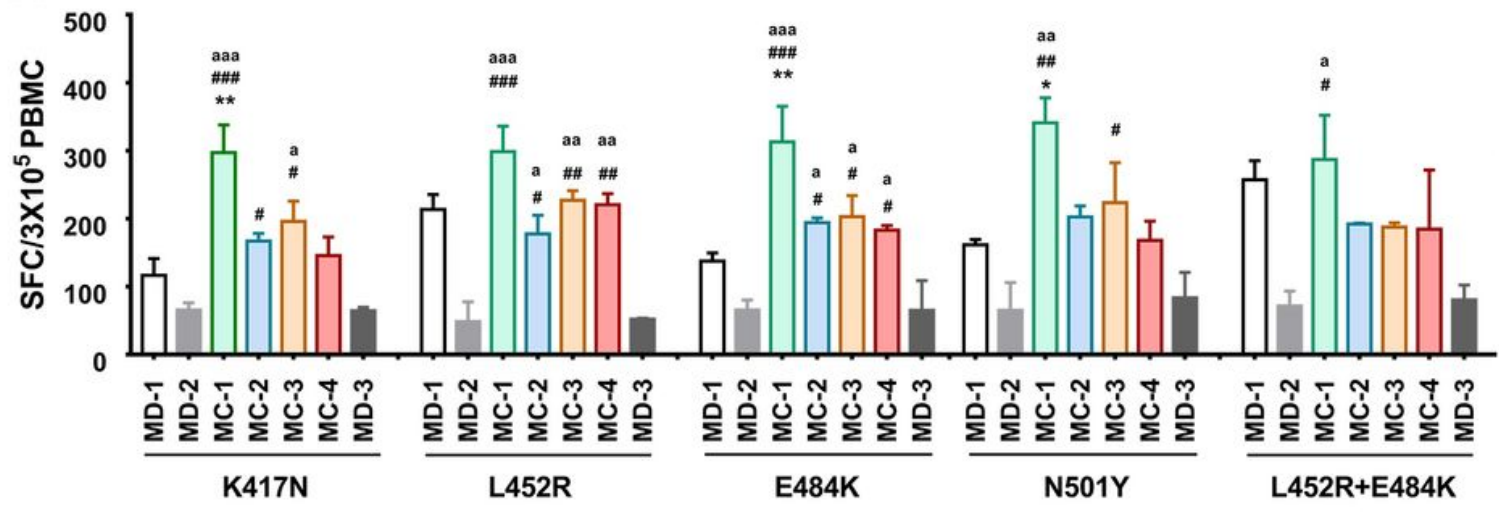

(c)

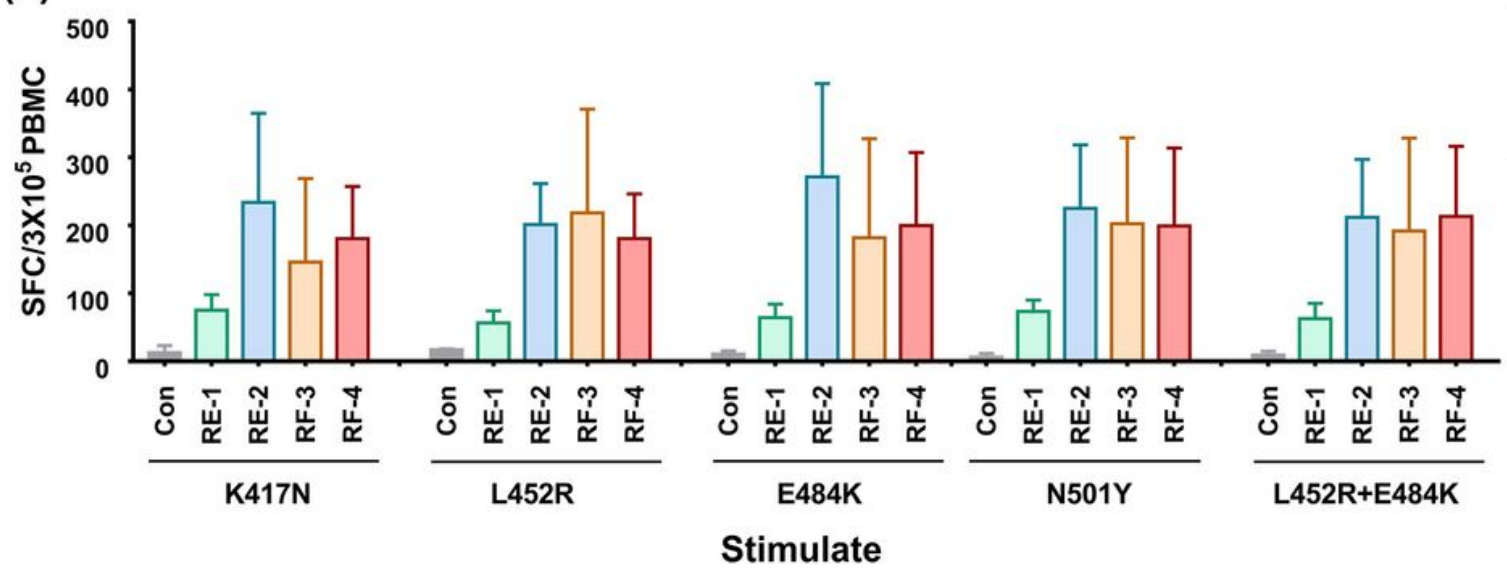

(b)

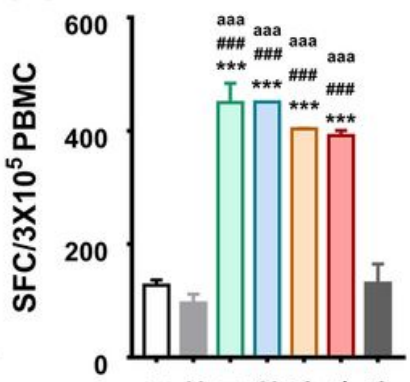

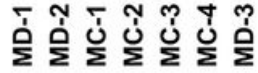

(d)

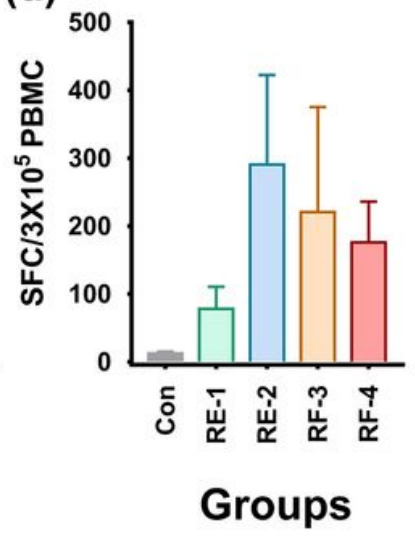

Figure 5

Development of a specific T cell response against different antigens from variants in individuals immunized with the heterologous vaccine administered via the intradermal route. (a) Specific T cell responses against RBD peptides with 5 variants were induced in immunized mice of the MC group (immunized with both the inactivated vaccine and K-S antigen). (b) Specific T cell responses against $\mathrm{N}$ peptides were induced in immunized mice of the MC group (immunized with both the inactivated vaccine 
and K-S antigen). (c) Specific T cell responses against RBD peptides with 5 variants were induced in immunized macaques of the RE and RF groups (immunized with both the inactivated vaccine and K-S antigen). (d) Specific $T$ cell responses against $\mathrm{N}$ peptides were induced in immunized macaques of the $\mathrm{RE}$ and RF groups (immunized with both the inactivated vaccine and $\mathrm{K}-\mathrm{S}$ antigen). Blood samples were obtained on day 28 after boosting with the K-S antigen, as well as those of three normal monkeys (Con) *, $p<0.05 ; * \star, p<0.01 ; * \star * ; p<0.001$ versus MD-1 group. \#, $p<0.05 ; \# \#, p<0.01 ; \# \# \#, p<0.001$ versus MD-2 group. a, $p<0.05$; aa, $p<0.01$; aaa, $p<0.001$ versus MD-3 group.

(a)

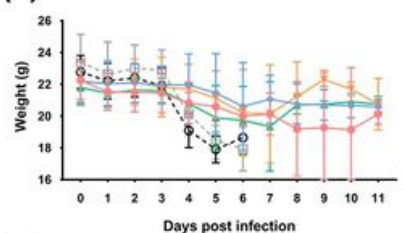

(c)

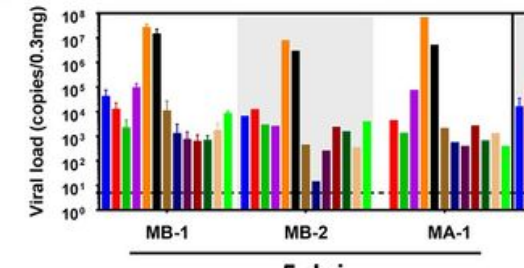

(e)

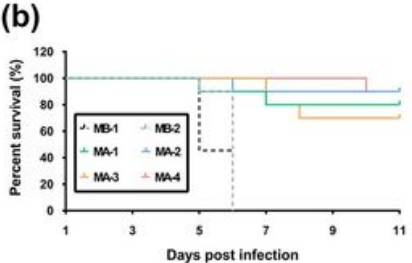

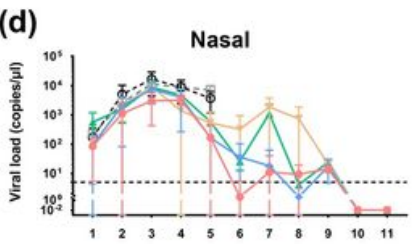

Days post infection

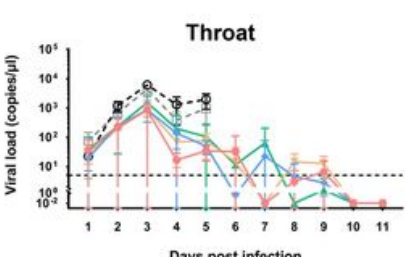

Days post infection

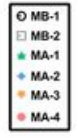

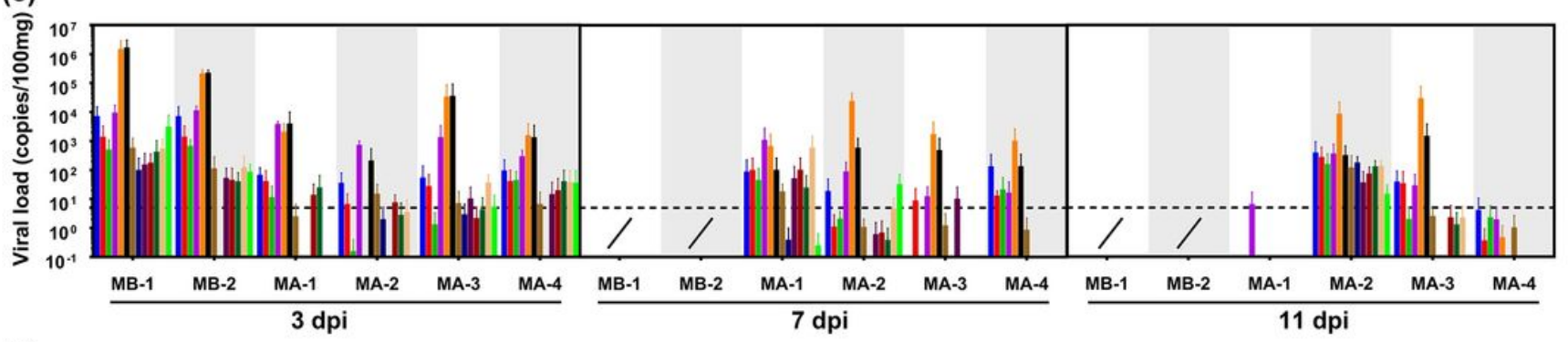

(f) Con MB-1

MB-2

MA-1

MA-2

MA-3

MA-4

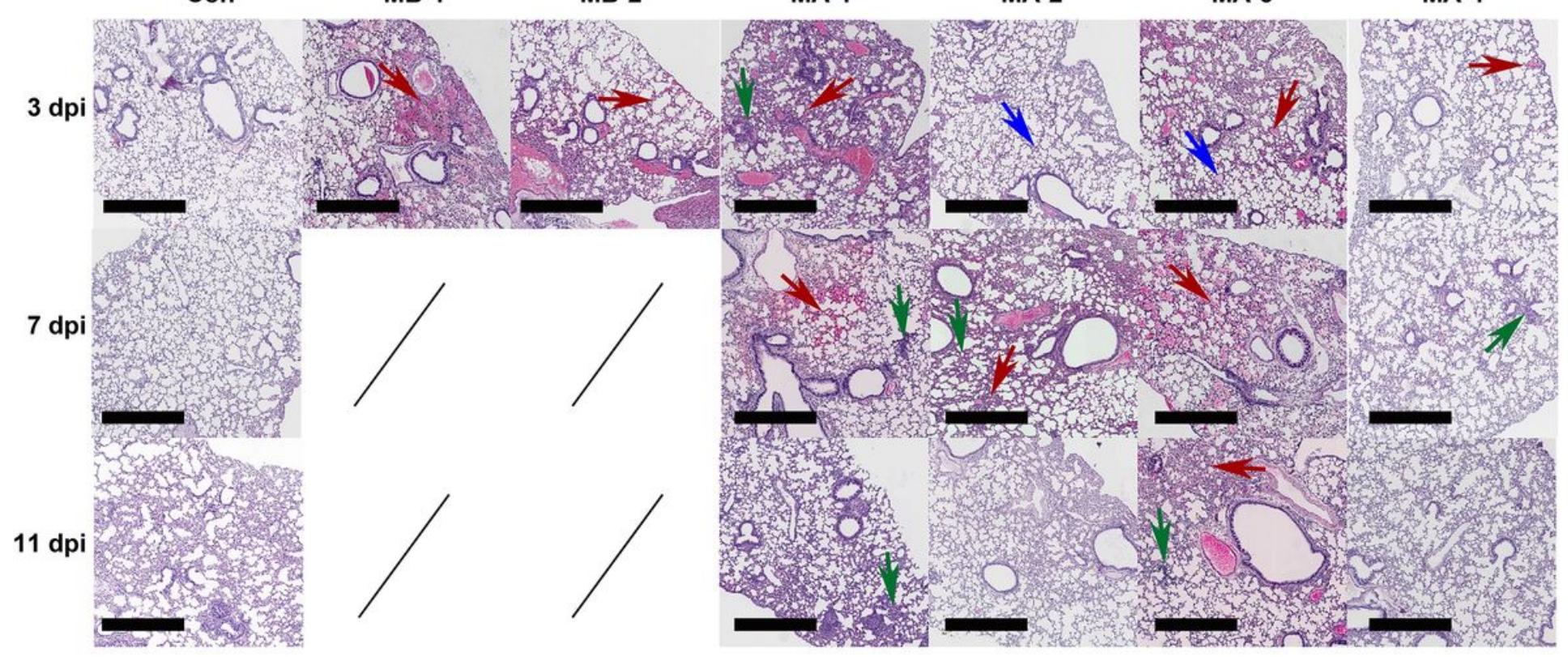

Figure 6 
Immunity elicited in $\mathrm{ACE}+/+$ transgenic mice by the heterologous vaccine administered intradermally enables the prevention of infection caused by the B.1.617.2 strain. (a) Body weight changes during viral challenge in $\mathrm{ACE}+/+$ transgenic mice immunized with the heterologous vaccine administered intradermally. ( $n=10$ per group) (b) Percent survival during viral challenge in $A C E+/+$ transgenic mice immunized with the heterologous vaccine administered intradermally. ( $n=10$ per group) (c) Viral loads of the various tissues or organs from the death mice during viral challenge. The detection threshold (5 copies/ $\mu \mathrm{l}$ ) is shown by the dotted line. (d) Viral loads in the nasal and oral cavities during viral challenge in $\mathrm{ACE}+/+$ transgenic mice immunized with the heterologous vaccine administered intradermally. The detection threshold ( 5 copies $/ \mu \mathrm{l}$ ) is shown by the dotted line. As the mice of the MB-1 and MB-2 group all died at day 6 after infection, there is no viral load data. (e) Viral loads in various organs and tissues during viral challenge in $\mathrm{ACE}+/+$ transgenic mice immunized with the heterologous vaccine administered intradermally. The detection threshold $(5$ copies $/ \mu$ l) is shown by the dotted line. Samples of organs and tissues were obtained on days 3, 7 and 11 after viral infection. As the mice of the MB-1 and MB-2 group all died at day 6 after infection, there is no viral load data. (f) Pathological observation of lung in ACE $+/+$ transgenic mice immunized with the heterologous vaccine administered intradermally. Samples of organs and tissues were obtained on days 3, 7 and 11 after viral infection. Bleeding (red arrow), edema (blue arrow), alveolar wall thickening (green arrow). Bar, $600 \mu \mathrm{m}$.

\section{Supplementary Files}

This is a list of supplementary files associated with this preprint. Click to download.

- TableS1.docx

- figS1.tif

- figS2.tif 